\title{
A Cluster-Focus of Multiple Sclerosis at Henribourg, Saskatchewan
}

\author{
Walter J. Hader, Donald G. Irvine and H. Bruno Schiefer
}

\begin{abstract}
This study presents the clinical characteristics of 8 victims of multiple sclerosis from the hamlet of Henribourg, Saskatchewan with a population of less than 75 people. A diligent victim of the disease had observed that six female classmates from the early 1940's had later developed multiple sclerosis. Two male military personnel who had also resided briefly in close proximity, during the same common exposure time, also later developed multiple sclerosis. The mean onset time of developing the disease after leaving the area was 20 years. This cluster-focus suggests a common exposure to an environmental factor or a common infective agent in the etiology of multiple sclerosis.

RÉSUMÉ: Un îlot-foyer de sclérose en plaques à Henribourg, Saskatchewan Cette étude présente les charactéristiques cliniques de 8 patients atteints de sclérose en plaques résidant à Henribourg, un hameau de la Saskatchewan donı la population est de moins de 75 personnes. Une victime de la maladie avait remarqué que six femmes qui étaient consoeurs de classe au début des années 40 ont par la suite développé une sclérose en plaques. Deux militaires de sexe masculin, qui avaient également résidé brièvement dans le voisinage immédiat pendant la même période d'exposition, ont également développé une sclérose en plaques par la suite. La maladie est apparue en moyenne 20 ans après que le patient ait quitté la région. Cet îlot-foyer suggère une exposition commune à un facteur environnemental ou à un agent infectieux commun dans l'étiologie de la sclérose en plaques.
\end{abstract}

Can.J. Neurol. Sci. 1990; 17:391-394

Multiple sclerosis is known for its peculiar geographical occurrence, with increasing incidence at higher latitudes in the northern and southern temperate climate areas. There is increasing evidence that multiple sclerosis is a disease acquired in childhood' with a long latent period before clinical symptoms appear. ${ }^{2}$ The disease has been estimated to begin between birth and 15 years, ${ }^{3}$ and in the case of clusters with the patients living close together at least 5 to 10 years before the onset of symptoms. ${ }^{4}$

Migrant studies 5,6 suggest the possibility of environmental factors in the etiology of multiple sclerosis. Data on the effect of migration point more to an environmental influence than to an infective cause for the disease, but the nature of this geographically-bound, predisposing factor remains unknown. ${ }^{7}$ Recent twin studies have strongly suggested a genetic predisposition to multiple sclerosis. 8

Another feature of the geographic occurrence of multiple sclerosis is the existence of "cluster-foci" or "hot spots". These are small geographic areas $9.10,11,12$ where the frequency of cases is far higher than expected for areas at the same latitude. A clusterfocus is defined as a site where several or many cases of multiple sclerosis occurred at the same time, or where several patients with this disease grew up together, or were "exposed" to the specific locale over the same period of time. Cluster-foci are typically detected in small towns, villages or hamlets where they are likely to be more conspicuous and where people are more likely to be exposed to a unique set of conditions than is the case in larger centers.

The purpose of this study was to investigate the concerns expressed by one of the residents ${ }^{13}$ from the hamlet of Henribourg, Saskatchewan, who later developed multiple sclerosis. Henribourg hamlet is located in the Rural Municipality of Buckland (\#491) in the Province of Saskatchewan. By latitude and longitude, it is at $53^{\circ} 24^{\prime}$ north, $105^{\circ} 37^{\prime}$ west, while in terms of legal land description in Canada, it is part of the south half of the SE $1 / 4$ of section 16 , township 51 , range 25 , west of the 2 nd meridian. It is 486 metres above sea level.

During the summer, this hamlet is significantly cooler than Prince Albert, (a city located $16 \mathrm{~km}$ south-west) and the more southerly locations in Saskatchewan, while in winter, Henribourg lies in a small circular zone with exceptionally cold weather, even for Saskatchewan. In this zone, January temperatures of below $-54^{\circ} \mathrm{C}$ have been recorded. Average temperatures are $-19^{\circ} \mathrm{C}$ in January, and $18^{\circ} \mathrm{C}$ in July; the annual precipitation averages $38 \mathrm{~cm}$ and winds are predominantly from the northwest. Regional sunshine totals 1,200 hours per year.

\section{METHODOLOGY}

A questionnaire was sent initially to all contacts and responders and arrangements made to interview and examine all possible cases, and obtain medical records.

From the Department of Rehabilitation Medicine, University of Saskatchewan, Royal University Hospital, (W.J.H.) and the Toxicology Research Centre, (D.G.I., H.B.S.) University of Saskatchewan, Saskatoon

Received December 28, 1989. Accepted in final form August 21, 1990

Reprint requests to: Walter Hader, M.D., Department of Rehabilitation Medicine, Royal University Hospital, Saskatoon, Saskatchewan, Canada S7N 0X0 
The geography of Henribourg Hamlet was studied by direct observations on field trips, combined with extensive use of atlases, specialized maps, aerial photographs, archival materials including old well surveys, homestead records, school records from 1935 to 1950 , and the municipal history book. ${ }^{14}$

Long-time residents in the district were consulted for precise location of childhood homes of the specific students, and for insights into life-styles and changes in Henribourg. The studies on the geochemistry of soil and water at Henribourg and a control area have been reported elsewhere. ${ }^{15.16}$

\section{Clinical Characteristics}

From the hamlet of Henribourg, six female school children and two non-school residents (military personnel who lived in close proximity for varying periods of time) developed multiple sclerosis.

Five of the six females had clinical reviews and examinations; information in writing was received from the remaining one. Communication in writing was received from the wife of the one deceased male on whom an autopsy had been performed. The other male provided information by telephone and a completed questionnaire. Seven of the eight patients had a diagnosis of clinical definite multiple sclerosis confirmed by neurologists.
Seven of the patients were born in Saskatchewan, all of the females and one male (Table 1). Two of the females were born in Henribourg. Four females had the onset of multiple sclerosis in Saskatchewan. Two of the females were sisters.

The average age of onset of M.S. was 37 years in the females and 45 years for the two males. The average latency to onset of initial symptoms of multiple sclerosis in the females after leaving school was 20 years (range 15-27 years). Both males had onsets of multiple sclerosis in British Columbia; one 13 years and the other 24 years after leaving Henribourg.

The school records from 1935 to 1950 indicate a total of 283 students representing 102 family names. During the years 1937-1942, five of the female subjects were attending the small three-room school, while two of these and a (new) sixth girl of the series were attending the school in 1946-47. The shaded area in Figure 1 shows the years of common exposure in the school for all but one of the females.

The water supply for the school was taken from the one main village well and dispensed to the children from a large crock that was stationed near the door of the school and it is presumed that the same water ladle was used for all the students. Four of the females lived in the hamlet and two on nearby farms. Male subject No. 7, a short-term resident, lived in the same house on the farm as female No. 4 who also later developed multiple sclerosis.

Table 1. Clinical Characteristics of Multiple Sclerosis Cases from Henribourg Hamlet

\begin{tabular}{|c|c|c|c|c|c|c|c|c|c|c|}
\hline \multicolumn{2}{|l|}{ Subjects } & \multirow{2}{*}{$\begin{array}{c}\begin{array}{c}\text { Date of } \\
\text { Birth }\end{array} \\
1929\end{array}$} & \multirow{2}{*}{$\frac{\text { Place of Birth }}{\text { Henribourg }}$} & \multirow{2}{*}{$\begin{array}{c}\begin{array}{c}\text { Years in } \\
\text { School }\end{array} \\
11\end{array}$} & \multirow{2}{*}{$\begin{array}{c}\begin{array}{c}\text { Date } \\
\text { of Onset }\end{array} \\
1962\end{array}$} & \multirow{2}{*}{$\begin{array}{c}\begin{array}{c}\text { Age of } \\
\text { Onset }\end{array} \\
33\end{array}$} & \multirow{2}{*}{$\begin{array}{c}\begin{array}{c}\text { Place } \\
\text { of Onset }\end{array} \\
\text { Ontario }\end{array}$} & \multirow{2}{*}{$\begin{array}{c}\begin{array}{c}\text { Duration } \\
\text { of MS }\end{array} \\
23\end{array}$} & \multirow{2}{*}{$\frac{\text { EDSS }^{*}}{7.5}$} & \multirow{2}{*}{$\frac{\text { Year }}{1985}$} \\
\hline Female & 1 & & & & & & & & & \\
\hline & 2 & 1930 & Sask. & 11 & 1971 & 41 & Sask. & 10 & 10.0 & $1981 * *$ \\
\hline & 3 & 1927 & Sask. & 5 & 1962 & 35 & Sask. & 20 & 1.0 & 1982 \\
\hline & 4 & 1928 & Henribourg & 10 & 1971 & 43 & Sask. & 15 & 8.0 & 1986 \\
\hline & 5 & 1926 & Sask. & 7 & 1959 & 33 & Sask. & 27 & 6.5 & 1986 \\
\hline & 6 & 1934 & Sask. & 4 & 1970 & 36 & U.S.A. & 15 & 1.5 & 1985 \\
\hline \multirow[t]{2}{*}{ Male } & 7 & 1919 & Manitoba & $* * *$ & 1966 & 47 & B.C. & 21 & 6.0 & 1987 \\
\hline & 8 & 1913 & Sask. & $* * *$ & 1956 & 43 & B.C. & 25 & 10.0 & $1981 * *$ \\
\hline
\end{tabular}

*Kurtzke Expanded Disability Status Scale. ${ }^{27}$

**Died in 1981

*** Did not attend school in Henribourg

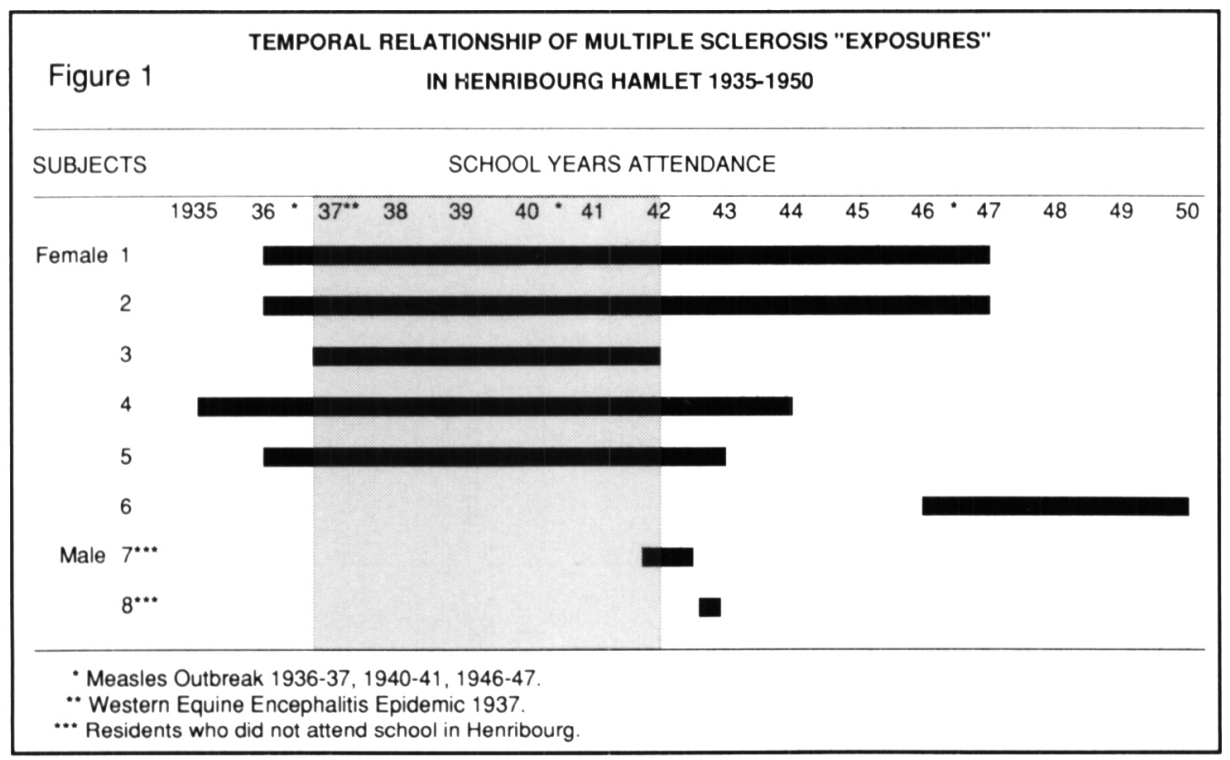


Male resident No. 8 and his wife, lived in a structure about 40 metres from the common well which was the source of water supply and also next door to the house where female No. 6, who moved to Henribourg in 1946 and also developed multiple sclerosis. She was the only one who ever returned to Henribourg for a three month stay in 1966. She subsequently had an onset of optic neuritis in 1970 in the United States.

Male subject No. 7 had married a lady from this same house three years earlier, but there was no personal contact of these individuals with female subject No. 6 who lived there later. There was also no personal contact between the males who were stationed at different times on military duty in Henribourg.

Three measles outbreaks were reported by the village residents and there was a vague recall of an outbreak of Western equine encephalitis in 1937 in Saskatchewan, but no apparent effect on the animals in this area.

Six of the subjects are still living. One female died at age 51 and one male died in 1981 at age 68.

\section{DISCUSSION}

These eight cases of multiple sclerosis from the hamlet of Henribourg, Saskatchewan constitute a cluster-focus. The population denominator at risk over the fifteen year period includes the 283 school children, the 75 hamlet residents, the parents living in the surrounding area and the only two known military personnel.

All of the victims were born in high risk areas and all had the onset of their disease in high risk areas in North America, where the prevalence rates average $100 / 100,000,17,18,19$ The incidence rate for Saskatchewan is estimated at 4.8/100,000. ${ }^{18}$

All of the female classmates grew up together and the military personnel were exposed to this specific locale in the same period. In this study the incidence and the geographic location of multiple sclerosis seem closely related, suggesting an environmental agent as the cause of the disease. While there may be an environmental and/or genetic predisposition to the disease, it is uncertain whether these alone will lead to clinical multiple sclerosis or whether a precipitating factor later on in life, is required to initiate the demyelinating process. The six females attended the same school which had an average enrolment of 83 children per year, in three crowded classrooms, one in the basement of the school. Seven of the eight persons definitely were exposed to the village water supply for the common well. The chemical composition of the drinking water or food at that period of exposure may constitute a link and a potential positive risk factor for the disease. 15.16

Several authors have described clusters in which either the present homes or the earlier childhood homes of the M.S. patients were extremely close together. These include Campbell et al, 20 with six cases living less than 450 metres from each other; Sutherland, ${ }^{21}$ reporting three neighbours on the same street; and Eastman et al 10 with eight of their fourteen cases having lived in close proximity along the main street of a small Massachusetts town of 10,000 persons some 23 years before the onset of clinical symptoms. This was in the early 1930's during a period when the water supply had been contaminated.

In a rural setting, Millar ${ }^{22}$ found eight cases of M.S. living in an area of approximately five square kilometres. It seems, from the work of Wikstrom and $\mathrm{Palo}^{23}$ that clustering is much more evident if the childhood home, rather than the present domicile is used as the basis for the spatial analyses.

In the case of the Henribourg Hamlet, the children who developed M.S. in later years were certainly living very close together. Yet an examination of Henribourg on the basis of "present domicile" of persons with M.S. would reveal nothing of particular interest or significance. Statistical analyses in two other reported studies have indicated the absence of clustering of cases of multiple sclerosis. ${ }^{24.25}$

Temporal and spatial variation in the incidence of disease can provide valuable clues to disease etiology. Consequently studies examining variation in the incidence of disease in small geographical areas over relatively short periods of time have received considerable attention from the public and scientific communities. These time-space clusters are often perceived as evidence of the presence of infectious or environmental agents despite the fact that rarely are any clear causal links established.28

Because of the localized nature of time-space clusters, population data necessary for the calculation rates are frequently unavailable. Furthermore, as attention is often drawn to clusters prior to the specification of etiologic hypotheses, conventional statistical tests are generally viewed as inappropriate. As a result a number of special statistical techniques have been developed to analyse data from this type of study.

A review by Schottenfeld and Fraumeni ${ }^{29}$ involving a comparison of the best known special statistical techniques, those of Knox, ${ }^{30}$ Ederer et al, ${ }^{31}$ Barton et al ${ }^{32}$ and Mantel, ${ }^{33}$ concluded that it was not possible to recommend a particular method as best. More recently Roberson ${ }^{34}$ has criticized the Knox and Mantel methods, as results have been shown to be affected by perturbations in underlying population distributions.

Insofar as denominator population at risk data are available to us and the focus of this study is on space clustering and not necessarily on a time-space interaction, we have applied the approach proposed by Breslow and Day 35 and calculated the exact $95 \%$ confidence intervals based on the Poisson distribution probabilities with the results indicating that this cluster cannot be explained by chance alone.

However, in so doing we recognize that we have not escaped the epidemiological issues involved in the interpretation of disease clusters in general. These issues have been recently revicwed by Rothman ${ }^{36}$ and pertain by and large to issues of risk factor assessment and confounding variables.

In studying apparent clustering, there is a risk of making one or other of two quite different types of error. Type I error is the reporting of a cluster where, in fact, no real cluster - but just a chance occurrence - exists. Type II error is to conclude there is no true cluster, and hence the decision not to report a cluster when in fact a real cluster does exist. In choosing a Type I error, the risk is that Henribourg is a "false positive".

We agree with Langmuir ${ }^{37}$ that "The constructive approach to the study of clusters is not to develop highly refined statistical tests to determine whether a certain cluster might have resulted by chance alone but rather to investigate each cluster as it is reported and see if additional associations of possible interest can be found".

Evidence from the literature suggests a predisposing environmental exposure in early childhood. An additional environmental factor could be implicated as a triggering factor for the onset of the disease later in life. 
The Orkney Island study suggests two environmental exposures before the onset of the disease, ${ }^{26}$ however no evidence of clustering was found in the nearby Shetland Islands. The average incubation time of 20 years after common exposure to an etiological environmental agent suggests, in our study, that the two male military personnel who were ages 22 and 29 at the time of residence in Henribourg hamlet, and had the onset of their disease 24 and 13 years later respectively, had the initial exposure to a common agent in Henribourg rather than during childhood. Yet this could represent a second exposure or "reinforcement", with the clinical manifestation presenting approximately 20 years later.

Since no cases of M.S. have been found before or after this group from Henribourg, the common time of exposure would suggest a point-source infection or environmental agent at the time in question. Three epidemics of measles were recorded and seven of the weight persons were probably exposed to one or more of the measles outbreaks, but no direct causal connection can be established from this information.

Several mechanisms are possible whenever a geographic relationship to a disease is found. In multiple sclerosis, where there is apparently a long latent period between the predisposing exposure and onset of the clinical condition, there is a further complicating time factor. It is quite possible that the important geographically-linked factor may have disappeared between the time of childhood exposure and the first opportunity for researchers to examine a site such as Henribourg. Before drawing conclusions regarding one particular locale, additional studies involving other locations are indicated.

\section{ACKNOWLEDGEMENTS}

We are grateful to Mrs. Sylvia Hall, who originally perceived the significance of the Henribourg cluster and brought its research potential to our attention; to Mr. Arthur Linder (Downsview, Ontario) who initiated our conversations with Mrs. Hall; to Dr. R. West of Saskatchewan Health, for providing epidemiological information and suggestions; to Dr. P. Seliski, Department of Community Health and Epidemiology, University of Saskatchewan for statistical advice on cluster studies analysis; to D.S. Hancock for graphics; financial support from Mr. B. Prasse, Northway Chevrolet Oldsmobile Ltd., Prince Albert, Saskatchewan and the Birch Hills Multiple Sclerosis Club, Saskatchewan; and Carol Kettles and Bev Atkinson for word processing and manuscript typing.

\section{REFERENCES}

1. Millar JH. In: Multiple sclerosis. A disease acquired in childhood. Charles \& Thomas Publisher 1971; 2: 14-18.

2. Schapira K, Poskanzer OC, Miller H. Familial and conjugal multiple sclerosis. Brain 1963; 86:315-332.

3. Kurtzke JF. On the time of onset in multiple sclerosis. Acta Neurol Scand 1965; 41: 140-158.

4. Bammer H, Schaltenbrand G. Disseminated sclerosis: a survey in forty-six communities of western lower franconia. Acta Psychiat Neurol Scand 1960; 35(147): 51-63.

5. Alter M, Leibowitz U, Speer J. Risk of multiple sclerosis related to age at immigration to Israel. Arch Neurol 1966; 15: 234-237.

6. Dean G, Kurtzke JF. On the risk of multiple sclerosis according to age at immigration to South Africa. Brit Med J 1971; 3: 725-729.

7. Acheson Ed. The epidemiology of multiple sclerosis. In: Matthews WB, ed. McAlphine's multiple sclerosis. Edinburgh: Churchill Livingstone $1985 ; 20$.

8. Ebers GC, Bulman DE, Sadovnick AD, et al. A population-based study of multiple sclerosis in twins. N Engl J Med 1986; 315 : 1638-1642.
9. Deacon WE, Alexander L, Siedler HD, Kurland LT. Multiple sclerosis in a small New England community. New Eng J Med 1959; 261: 1059-1061.

10. Eastman R, Sheridan J, Poskanzer DC. Multiple sclerosis clustering in a small Massachusetts community with possible common exposure 23 years before onset. New Engl J Med 1973; 289: 793-794.

11. Koch MJ, Reed D, Stern R, et al. Multiple sclerosis: a cluster in a small northwestern United States community. JAMA 1974; 228: 1555-1557.

12. Murray TJ. An unusual occurrence of multiple sclerosis in a small rural community. Can J Neurol Sci 1976; 3: 163-166.

13. Martin D. A diligent victim helps unearth clues to multiple sclerosis. The New York Times 1985; March 19: 23 (Col. 1-6).

14. Buckland History Book Committee. Buckland's heritage. TurnerWarwick Printers, North Battleford, Saskatchewan, Canada 1980.

15. Irvine DG, Schiefer HB, Hader WJ. Geotoxicology of multiple sclerosis. The Henribourg Saskatchewan cluster focus I: the water. Sci Tot Envir 1989; 84: 45-49.

16. Irvine DG, Schiefer HB, Hader WJ. Geotoxicology of multiple sclerosis. The Henribourg Saskatchewan cluster focus 2: the soil. Sci Tot Envir 1988; 77: 175-188.

17. Hader WJ, Elliot M, Ebers GC. Epidemiology of multiple sclerosis in London and Middlesex County, Ontario, Canada. Neurology 1988: 38: 617-621

18. Hader WJ. Prevalence of multiple sclerosis in Saskatoon. Can Med Assoc J 1982; 127: 295-297.

19. Sweeney VP, Sadovnick AD, Brandejs V. Prevalence of multiple sclerosis in British Columbia. Can J Neurol Sci 1986; 13: 47-51.

20. Campbell AMG, Herdan G, Tatlow WFT, et al. Lead in relation to disseminated sclerosis. Brain 1950; 73: 52-71.

21. Sutherland JM. Observations on the prevalence of multiple sclerosis in northern Scotland. Brain 1956; 79: 635-654

22. Millar JHD. Multiple sclerosis, two high risk areas in northern Ireland. J Irish Med Assoc 1966; 59: 138-143.

23. Wikstrom J, Palo J. Studies on the clustering of multiple sclerosis in Finland. I. Comparison between the domiciles and places of birth in selected subpopulations. Acta Neurol Scand 1975; 51: 85-98.

24. Hargreaves ER, Merrington M. A note on the absence of "clustering" of multiple sclerosis cases. J Chron Dis 1973; 30: 217-224.

25. Neutel Cl, Walter SD, Mousseau G. Clustering during childhood of multiple sclerosis patients. J Chron Dis 1977; 30: 217-224.

26. Poskanzer DC, Walker AM, Prenney LB, et al. The etiology of multiple sclerosis: temporal-spatial clustering indicating two environmental exposures before onset. Neurology 1981; 31: 708-713.

27. Kurtzke JF. Rating neurologic impairment in multiple sclerosis: an expanded disability status scale (EDSS). Neurology 1983; 33: 1444-1452.

28. Caldwell GC. Twenty-two years of cancer cluster investigations at the centers for disease control. Am J Epidemiol 1990; 132: S43-S47.

29. Schottenfeld D, Fraumeni JF. Cancer epidemiology and prevention. W.B. Saunders 1982; 21: 391-407.

30. Knox G. Epidemiology of childhood leukemia in Northumberland and Durham. Brit J Prev Med 1964; 18: 17-24.

31. Ederer F, Myers MH, Mantel N. A statistical problem in space and time: do leukemia cases come in clusters? Biometrics 1964; 20 : 626-638.

32. Barton DE, David FN, Merrington M. A criterion for testing contagion in time and space. Ann Hum Genet (London) 1965; 29: 97 102.

33. Mantel $\mathrm{N}$. The detection of disease clustering and a generalized regression approach. Cancer Res 1967; 27: 209-220.

34. Roberson PK. Controlling for time-varying population distributions in disease clustering studies. Am J Epidemiol 1990; 132: S131S135.

35. Breslow NE, Day NE. Statistical methods in cancer research. Vol 2: the design and analysis of cohort studies. Oxford: University Press 1988; 2: 48-79.

36. Rothman KJ. A sobering start for the cluster buster's conference. Am J Epidemiol 1990; 132: S6-S13.

37. Langmuir AD. Epidemiology of cancer: spatial-temporal aggregation. Cancer Res 1965; 25: 1384-1386. 